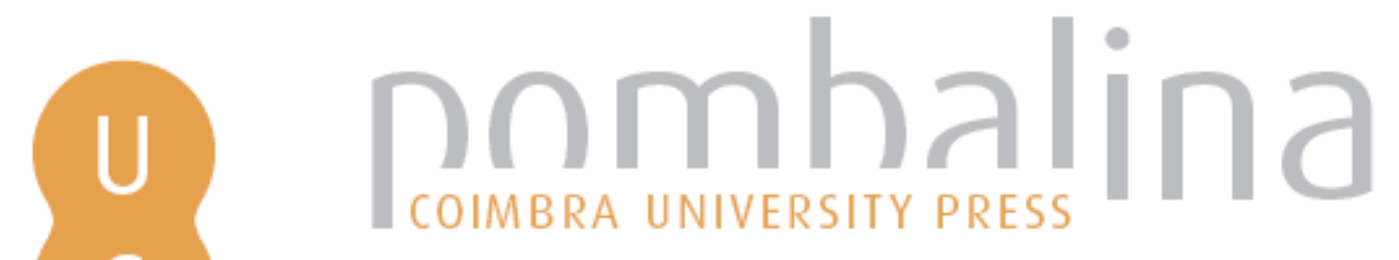

\title{
Egas Moniz e o Brasil
}

Autor(es): $\quad$ Antunes, João Lobo

Publicado por: Imprensa da Universidade de Coimbra

URL

persistente: URI:http://hdl.handle.net/10316.2/38456

DOI: $\quad$ DOI:http://dx.doi.org/10.14195/978-989-26-0764-1_20

Accessed : $\quad$ 26-Apr-2023 09:24:59

A navegação consulta e descarregamento dos títulos inseridos nas Bibliotecas Digitais UC Digitalis, UC Pombalina e UC Impactum, pressupõem a aceitação plena e sem reservas dos Termos e Condições de Uso destas Bibliotecas Digitais, disponíveis em https://digitalis.uc.pt/pt-pt/termos.

Conforme exposto nos referidos Termos e Condições de Uso, o descarregamento de títulos de acesso restrito requer uma licença válida de autorização devendo o utilizador aceder ao(s) documento(s) a partir de um endereço de IP da instituição detentora da supramencionada licença.

Ao utilizador é apenas permitido o descarregamento para uso pessoal, pelo que o emprego do(s) título(s) descarregado(s) para outro fim, designadamente comercial, carece de autorização do respetivo autor ou editor da obra.

Na medida em que todas as obras da UC Digitalis se encontram protegidas pelo Código do Direito de Autor e Direitos Conexos e demais legislação aplicável, toda a cópia, parcial ou total, deste documento, nos casos em que é legalmente admitida, deverá conter ou fazer-se acompanhar por este aviso.

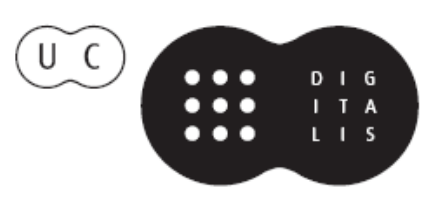


Faculdade de Medicina de Lisboa

Egas Moniz E o Brasil

João Lobo Antunes

Um dos traços mais vincados da personalidade de Egas Moniz era um cosmopolitanismo pouco comum no seu tempo. Muito cedo na sua vida profissional, ele percebeu que o seu aperfeiçoamento como clínico e, particularmente, como neurologista só podia ser conseguido pelo convívio com os grandes mestres da época. As visitas a Pierre Marie e Dejerine na Salpêtrière e, sobretudo, a Babinski na Pitié foram decisivas para a sua carreira científica, porque então a neurologia falava francês. Recorde-se que foi na sessão da Société Neurologique em Paris que Egas deu primeiramente a conhecer a sua invenção da angiografia ${ }^{1}$, logo após ter obtido uma imagem razoavelmente legível. Foi também Babinski que prefaciou a primeira monografia sobre o tema - Diagnostic des tumeurs cérébrales et Épreuve de l'Encephalographie Artérielle publicada em 1931.

Se é verdade que os laços científicos mais fortes o uniam à França, o seu afecto mais profundo ligava-o ao Brasil. É possível que para tal não fosse indiferente o facto deste ser o país de origem de sua mulher, Elvira de Macedo Dias, nascida em 14 de Julho de 1884 no Rio de Janeiro.

Elvira foi uma companheira dedicada inteiramente à carreira do marido, a quem chamava "Antoninho", e Egas pagava-lhe com amorável devoção. Elvira era filha de um emigrante português, José Joaquim Dias, que instalara a primeira fábrica mecânica de sapatos no Rio e de uma cidadã brasileira, Matilde Flora de Macedo. No Rio nasceu também uma irmã, Estefânia, que viria a casar com António Caetano Macieira Júnior, advogado e político muito activo na Primeira República portuguesa — foi ministro da Justiça e dos Negócios Estrangeiros —, além de um irmão Álvaro que faleceu muito novo. Diz-se que os pais teriam morrido de desgosto, como se acreditava na altura, e as duas irmãs órfãs vieram então para Lisboa, onde uns tios as tomaram a cargo.

A vontade de Elvira de voltar à sua terra natal terá pesado na decisão de, em Julho de 1928, o casal viajar para o Rio a convite de Aloísio de Castro, professor da Faculdade de Medicina do Rio de Janeiro e ao tempo director do Departamento Nacional de Ensino. Esta visita, que Egas considerou "a mais emocionante jornada médica que

${ }^{1}$ A angiografia é uma técnica de diagnóstico, ainda hoje usada, que consiste na visualização radiográfica das artérias pela injecção de um meio de contraste radiopaco. 
realizei na minha vida de cientista", merece dois capítulos na sua autobiografia científica, Confidências de um Investigador Cientifico, publicada em 1949.

Assim, em Julho de 1928, seguem no Cap d'Ancona para o Rio. A descrição da chegada é típica do estilo literário de Egas, muito ao jeito naturalista da época:

"A noite tinha a serenidade morna do Inverno do Rio [...] O mar marulhava docemente na praia interminável, a que a luz do "colar de pérolas" emprestava cintilaçôes, na policromia dos reflexos e na estratificação da espuma que orlava o espreguiçar das ondas."

Ficaram instalados no Hotel Glória, com uma larga varanda sobre a Guanabara. A viagem foi um absoluto sucesso e foi amplamente noticiada pelos jornais do Rio e de S. Paulo.

Em 1 de Agosto Egas faz a primeira conferência da Faculdade de Medicina do Rio sobre angiografia, projectando trinta diapositivos. No dia seguinte fala na Academia Nacional de Medicina a que presidia o Prof. Miguel Couto que, num extraordinário arroubo oratório, dizia que Egas ficara "cansado da serenidade" e "não seria um português, não seria um peito lusitano se tivesse medo de queimar o céu fustigando o seu corcel alípede para o alto"! A ciência ia resistindo à oratória académica...

Dois dias depois, faz uma comunicação na Sociedade Brasileira de Neurologia, Psiquiatria e Medicina Legal, de que fora feito sócio honorário e, mais tarde, na Sociedade de Medicina e Cirurgia do Rio de Janeiro. É no Rio que Augusto Brandão Filho realiza no Hospital da Santa Casa a primeira angiografia fora da Europa. Egas diz que foi "feliz. A doente nada sofreu e o filme arteriográfico foi regular". Entretanto recebe um convite para ir até S. Paulo, onde o esperava um programa académico e social ainda mais carregado.

Disserta na Faculdade e na clínica do Professor Ovídio de Campos onde o cirurgião Ayres Neto realiza uma arteriografia. É aclamado sócio honorário da Sociedade de Medicina e Cirurgia Paulista e fala novamente, desta vez sobre a importância do método angiográfico na localização dos tumores. Visita o Hospital de Junquéry e o famoso Instituto do Butantan onde se investiga ainda hoje o tratamento das mordeduras de ofídios. Egas é recompensado com um banquete opíparo no Automóvel-Club - "Excelente cardápio", comenta, consolado. A Folha da Noite de S. Paulo conta ainda que no Hotel Esplanada, onde estava hospedado,

"o notável clínico atendeu a vários enfermos que procuraram, sem cobrar absolutamente nada, o que evidencia mais uma face do seu belo carácter de homem de ciência - o desinteresse e a grandeza de coração".

De volta ao Rio é recebido na Academia Brasileira de Letras com grande pompa, pois ele era então Presidente da Academia das Ciências de Lisboa. Aí Egas declara: "Os médicos carecem de uma vasta cultura geral e esta não se compreende sem uma sólida base artística”. No dia seguinte, é recebido no palácio de Catete pelo Presidente da República, Dr. Washington Luís, e na véspera da partida oferece, no hotel onde se alojara, um chá em que estiveram presentes vários ministros além do Embaixador de Portugal, Duarte Leite.

Egas é eleito Membro Honorário da Academia Nacional de Medicina do Rio de Janeiro e, mais tarde, numa segunda tentativa, membro correspondente da Academia 
Brasileira de Letras ocupando o lugar vago que pertencia a Carlos Malheiros Dias, e ainda do Instituto Brasileiro de História da Medicina.

Durante anos Egas manteve abundante correspondência com figuras destacadas da Neurologia e Psiquiatria brasileiras particularmente Pacheco e Silva e Aloísio de Castro. Este, que o visitava sempre que passava por Lisboa, escreve-lhe quando, em 14 de Março de 1939, Egas é vítima de um atentado cometitdo por um doente esquizofrénico dizendo: "à cabeceira do meu amigo [está] metade da minha alma”.

O neurologista brasileiro desempenhou também um papel decisivo na campanha para a atribuição do Prémio Nobel a Egas, algo que este perseguiu com extraordinária tenacidade logo após a invenção da angiografia cerebral, e que acabou por consagrar a leucotomia pré-frontal, a primeira tentativa de tratar cirurgicamente as doenças psiquiátricas.

O 1. ${ }^{\circ}$ Congresso Internacional de Psicocirurgia, realizado em Lisboa em 1949, deu ainda mais visibilidade internacional à operação de Egas e do seu colaborador Pedro Almeida Lima. Nessa reunião a sugestão do "Nobel" partiu da delegação brasileira e colheu apoio unânime das delegações estrangeiras aí presentes. Mas o contributo dos psiquiatras brasileiros foi, de facto, o mais decisivo. Mesmo antes, em 8 de Setembro de 1948 Aloisio de Castro, presidente da Academia Nacional de Medicina do Brasil, escreve a Egas dizendo que ia convencer os "paulistas" a promoverem a candidatura. Em 1 de Dezembro de 1948 escreve novamente a comunicar-lhe que conseguira fazer aprovar por unanimidade uma proposta nesse sentido. Em 26 de Dezembro de 1948 Egas, sempre diplomata, escreve a Pacheco e Silva agradecendo e dizendo que "mesmo que se não efective o bom desejo dos meus queridos amigos, sinto-me já suficientemente honrado muito além dos meus méritos". Em carta de 22 de Fevereiro de 1949 confirma que Pacheco e Silva lhe comunicara que tomara todas as providências para a candidatura, e que ele próprio fora à Delegação da Suécia entregar os documentos.

A delegação brasileira ao Congresso de Psicocirurgia era constituída por Pacheco e Silva, que presidia, Mattos Pimenta, Mário Yahn, Aníbal Silveira, Hélio Simões, António Carlos Barreto e Paulino Longo. Na sua proposta lia-se: "Considerando os inestimáveis serviços prestados à ciência e Humanidade pelas duas notáveis descobertas do Prof. Egas Moniz (...)” sugeriam “às associaçôes académicas dos diversos países que compareceram à conferência de Lisboa a apresentação do nome do insígnio científico português como digno por todos os títulos à candidatura ao prémio Nobel da Medicina”. Segue depois uma "justificativa” que não resiste a estabelecer a histórica e cansada comparação a que já recorrera Babinski no seu prefácio:

\footnotetext{
"Alienistas, neurologistas e neurocirurgiões de todas as partes do mundo, (...) são unânimes em proclamar e enaltecer os grandes méritos e o valor das descobertas do eminente sábio português cujas conquistas no terreno da ciência hão-de permanecer imperecíveis, como eterna será a glória dos navegadores portugueses que realizaram no mundo as maiores conquistas e as mais notáveis descobertas".
}

Em 27 de Outubro de 1949 chega finalmente a notícia de que o prémio lhe fora atribuído conjuntamente com Rudolf Hess, um fisiologista suíço.

A ligação de Egas ao Brasil iria manter-se até ao final da sua vida. Em 1951 Egas escreve o "prólogo" de um livro sobre leucotomia da autoria dos neurocirurgiōes 
brasileiros Mário Yahn, Matos Pimenta e Sette Júnior. Matos Pimenta fora o primeiro a executar essa intervenção no Brasil em 1936, no Hospital Junqueri em S. Paulo. Egas recorda a viagem que fizera e o papel que os colegas brasileiros tinham desempenhado na campanha do Nobel. O escrito é uma dissertação especulativa, algo frouxa, em que Egas conclui, apropriadamente, que a base da neurologia e sobretudo da "nova psiquiatria organicista" deve ser o estudo microscópico (hoje diríamos "molecular") do sistema nervoso. Nisto Egas é certeiro.

Em Janeiro de 1952 é inaugurada em Jacaré-Paguá, no Rio de Janeiro, no Hospital Colónia Juliano Moreira, pelo Ministro da Educação e Saúde do Brasil, a Clínica Egas Moniz dedicada à psicocirurgia. Egas manda uma mensagem recordando a viagem de 1928.

Quando Pedro Almeida Lima visita o Brasil já em final da vida de Egas, aquele escreve-lhe antes da partida uma carta em que dizia:

"Estou certo que todos apreciariam muito, talvez mesmo esperem, algumas palavras suas ou mesmo, se isso não fosse pedir demasiado, uma mensagem ou saudação que pudesse ser lida numa das minhas conferências".

Egas responde-lhe:

"Tenho-lhe inveja, meu caro Almeida Lima (...). Vai ver um dos mais belos países do Mundo e sobretudo os médicos de além-mar, sempre dispostos a receber com simpática atitude, o esforço de resultados pobros, persistentes e úteis dos colegas de aquém-mar."

O Brasil retribuiu sempre o carinho que Egas lhe devotava, e existem ruas com o seu nome em Fortaleza, no Rio e em São Paulo. Tal significa bem o reconhecimento do mérito da obra daquele que foi ao longo de uma vida muito atribulada, um político desiludido, um clínico carismático, um burguês rico, um humanista amador e, no fundo, um cientista improvável, cujas invençôes constituem um marco nas neurociências do século XX.

\section{REFERÊNCIAS}

MONIZ, Egas - Confidências de um Investigador Científico. Lisboa: Ática, 1949.

LOBO ANTUNES, João - Egas Moniz. Uma biografia. Lisboa: Gradiva, 2010. 